\title{
Role of Chemical Examination of the Stool in Diagnosis of Sugar Malabsorption in Children
}

\author{
P. SOEPARTO, E. A. STOBO, and J. A. WALKER-SMITH* \\ From the Department of Child Health, University of Sydney and the Royal Alexandra Hospital for Children, \\ Camperdown, N.S.W., Australia
}

\begin{abstract}
Soeparto, P., Stobo, E. A., and Walker-Smith, J. A. (1972). Archives of Disease in Childhood, 47, 56. Role of chemical examination of the stool in diagnosis of sugar malabsorption in children. Three chemical methods of examination of the stool used in the diagnosis of sugar malabsorption in children, namely, testing for reducing substances with 'Clinitest' tablets, $p \mathrm{H}$ estimation, and paper chromatography for sugar, were studied and the role of each in making the diagnosis was assessed. The demonstration of an abnormal amount ( $>\frac{1}{2} \%$ ) of reducing substances in the stools was confirmed to be a valuable screening test for sugar malabsorption. Stool chromatography was useful in diagnosing the type of sugar malabsorption present, but estimation of stool $p \mathrm{H}$ proved to be an unreliable screening test for the diagnosis of sugar malabsorption.
\end{abstract}

In 1961 Durand, Martino, and Lamedica used paper chromatography to demonstrate the presence of sugar in the stools of children, but in 1964 Kerry and Anderson in Melbourne developed a simple ward test for stool sugar testing, based on the use of Clinitest tablets, and this method has been used extensively since as a screening test for sugar malabsorption. Davidson in 1967 suggested that estimation of the $p \mathrm{H}$ of fresh stools was of value as a screening test for disaccharide malabsorption, but others considered such an estimation was not reliable (Holzel, 1967).

The purpose of this paper is to discuss the merits of various methods of chemical examination of the stool used in the clinical diagnosis of sugar malabsorption, and to discuss the types of sugar malabsorption which may be clinically diagnosed. Stools trom children suspected of having sugar malabsorption and stools from a small group of control infants have had the $p \mathrm{H}$ measured, the content of reducing substances estimated with Clinitest tablets, and any sugars present identified chromatographically. A diagnosis of sugar malabsorption was made on the basis of an assessment of the clinical state, chemical examination of the stools, and response to dietary management. The value of the stool findings in making the clinical diagnosis was assessed.

Received 23 August 1971.

* Wellcome Clinical Research Fellow.

\section{Methods}

Stool $p H$ estimation. As a preliminary study the reliability of testing stools with $p \mathrm{H}$ paper was investigated by comparing readings obtained in this way with those obtained using a glass electrode.

Lyphan indicator paper was used (Kloz, Berlin). This paper has a $p \mathrm{H}$ range between 1 and 11 . A portable pH meter with a glass electrode was used (Model 30C, Electronic Instruments Limited). 35 stools were examined in the ward immediately after they were passed. 9 more stools, freshly passed, were examined as soon as they reached the laboratory, i.e. a total of 44 stools were examined. The stools were collected on plastic to ensure complete collection.

The $p \mathrm{H}$ of all other stools was routinely tested with $p \mathrm{H}$ paper. If the stool was not tested freshly it was frozen and $p \mathrm{H}$ estimated after thawing. The interval after the stool was passed varied greatly. The effect of this freezing and variable time interval for measurement was evaluated. The effect of dilution of stools on $p \mathrm{H}$ readings was also observed in 17 stools. After testing for $\mathrm{pH}$, all stools were either examined immediately for sugar content or stored in the deepfreeze for later examination.

Examination of stools for sugar. A portion of the stool was diluted with twice its volume of water, and homogenized in a Vortex-Genie mixer. 15 drops of this mixture were transferred to a test-tube and a Clinitest tablet (Ames Company) added. The amount of reducing substances present was estimated as described by Kerry and Anderson (1964) and was rated as 
$0 \%, 0-\frac{1}{4} \%, \frac{1}{4} \%, \frac{1}{4}-\frac{1}{2} \%, \frac{1}{2} \%, \frac{3}{4} \%, 1 \%$, and $2 \%$. A finding of $\frac{1}{2} \%$ or more indicated the presence of an abnormal amount of sugar in the stool. A portion of the specimen was also tested again after acid hydrolysis (Kerry and Townley, 1965). Some specimens were examined freshly and again after freezing and the results compared.

The remaining suspension was centrifuged and the resulting supernate was used for spotting on to Whatman No. 1 chromatography paper. Descending one-way paper chromatography was used, with a $30 \mathrm{~cm}$ length of run, the solvent being a mixture of ethyl acetate, pyridine, and water $(13: 5: 4)$. A run of 16 hours gave satisfactory separation of sugars.

A modification of the alkaline silver nitrate method of Smith (1958) was used for locating the spots, as follows.

Silver nitrate. $3 \mathrm{ml}$ saturated solution of silver nitrate is added to $250 \mathrm{ml}$ acetone. A precipitate forms and is redissolved by drop-wise addition of water until solution is complete.

Sodium hydroxide. $5 \mathrm{ml}$ stock $40 \%$ aqueous solution of sodium hydroxide is added to $95 \mathrm{ml}$ ethanol.

The dried chromatogram was dipped through the silver nitrate solution and the acetone was blown off. It was then dipped through the sodium hydroxide solution when spots appeared which were brown or black in colour.

A fixing solution containing sodium thiosulphate and potassium metabisulphite was used to clear the background of the paper, and the paper was then washed in running water, and kept as a permanent record.

\section{Materials}

In all, 323 stools were examined from 146 children, of whom 14 were controls. Some were examined before diagnosis and some after starting dietary therapy. 132 of these children were being investigated for sugar malabsorption; 65 of the 132 children were in a gastroenteritis ward. These children had some form of diarrhoea when the strength of oral feeding had been increased in the convalescent period after acute gastroenteritis. 64 children were being investigated because of chronic diarrhoea and 17 children were neonates who developed diarrhoea after operation.

Two of the controls were normal breastfed neonates, 9 were neonates being investigated for disorders outside the alimentary tract, who were having feeds based on cow's milk, and 3 were infants aged between 1 and 3 months having cow's milk feeds.

The stools that were examined freshly in the $p H$ study were all collected on plastic. The remaining stools were collected on plastic, and a study was made over a period of time of the effect of collecting a sugarcontaining stool on an ordinary napkin rather than on plastic.

The gross appearance of each stool was noted and the adequacy of the specimen for examination was assessed before inclusion in the study.

\section{pH Study}

\section{Results}

Methodology. There was a satisfactory agreement between readings obtained with the $p \mathrm{H}$ meter and $p \mathrm{H}$ paper (Fig. 1). The greatest variation in

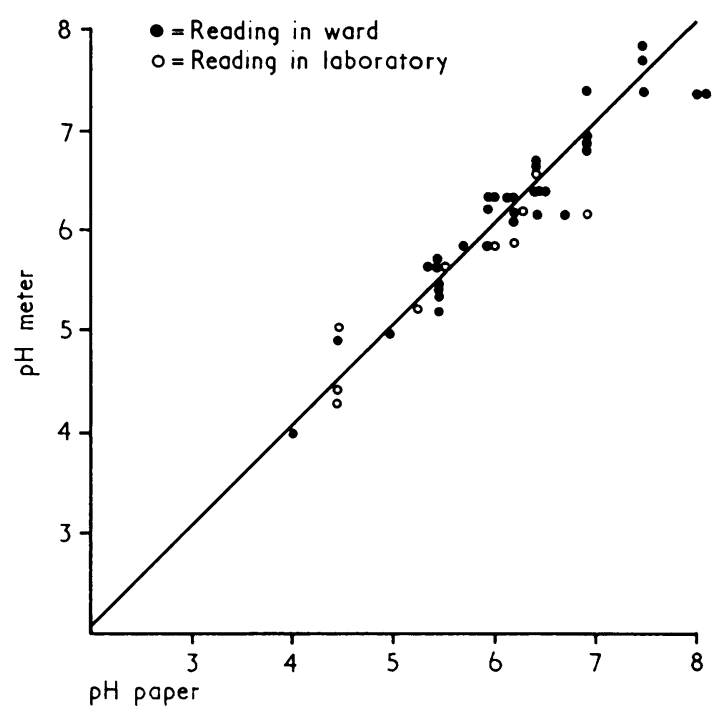

FIG. 1.-Relation between $\mathrm{pH}$ meter and $\mathrm{pH}$ paper readings.

readings was a $p \mathrm{H}$ paper value of 7 and a meter value of $6 \cdot 2$. However, on only 4 occasions was the difference between the methods greater than half a $p \mathrm{H}$ unit.

Results in 323 stools. There was no difference between $p \mathrm{H}$ readings of fresh stools and readings of the same stools after they had been frozen for varying intervals and then thawed. There was no difference between $p \mathrm{H}$ paper readings of undiluted stool and of stool diluted $1: \frac{1}{2}$ and $1: 1$ with water. There was a slight variation in $\mathrm{pH}$ meter readings, but not greater than $0 \cdot 2$ of a reading. There was a wide range of $p \mathrm{H}$ estimations in the stools examined which ranged from 4 to just over 7 . The values in 309 stools from children suspected of having sugar malabsorption are indicated in Fig. 2.

A stool $p \mathrm{H}$ of less than 6 is said to be characteristic of sugar malabsorption (Holzel, 1967), yet 14 stools had a $p \mathrm{H}$ of less than 5 , but contained only nonsignificant amounts of reducing substances (less than $\frac{1}{2} \%$ ). In 2 children progress stool examination revealed the presence of significant amounts of sugar, but in the remaining children progress stools were consistently free of sugar and 


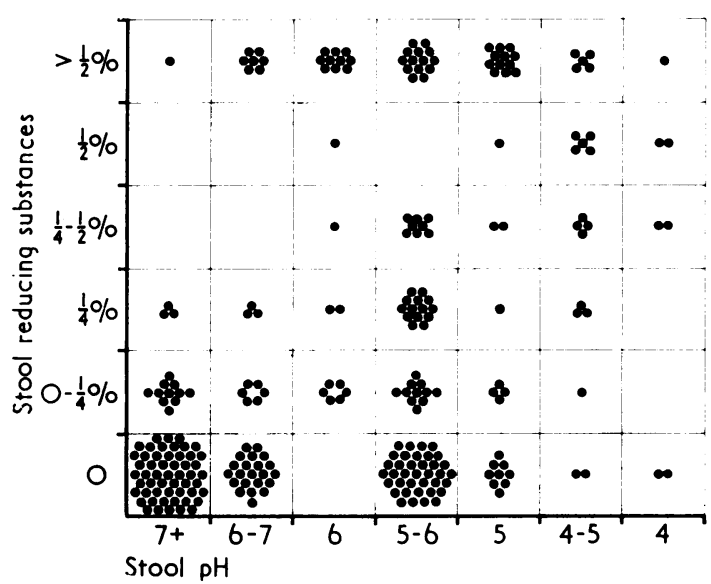

FIG. 2.-Relation between stool $\mathrm{pH}$ and stool reducing substances.

they subsequently thrived on a milk-containing diet. In addition, 18 stools contained a significant amount of reducing substances (more than $\frac{1}{2} \%$ ), yet the $p \mathrm{H}$ readings were 6 or more.

It is thus apparent from these results that stool $p \mathrm{H}$ is not always a reliable screening test for the diagnosis of sugar malabsorption in a large group of children with diarrhoea, but a stool $p \mathrm{H}$ of less than 5 in an individual child in the hospital situation, despite the absence of sugar, suggests that further stools should be examined for reducing substances.

Examination with Clinitest tablets. There were no reducing substances found in 177 of the stools from the 146 children being tested for sugar malabsorption. There was $\frac{1}{2} \%$ or more reducing substances in $\mathbf{5 0}$ stools. A non-significant level of reducing substances was found in the remaining stools (between $\frac{1}{4}$ and $\frac{1}{2} \%$ in $17, \frac{1}{4} \%$ in 26 , and between 0 and $1 \%$ in 39). The results are indicated in Fig. 2. After hydrolysis there was an apparent increase in the amount of reducing substances in 28 stools (Table I), though of varying degree and increasing to $\frac{1}{2} \%$ or more in 22 of these. In 3 children no reducing substances were present in their stools, but after acid hydrolysis a significant level appeared to be present $\left(\frac{1}{2}-\frac{3}{4} \%\right)$. Yet in only 7 was sucrose or its component monosaccharides detected on the chromatogram. 6 stools in the controls contained $\frac{1}{4} \%$ reducing substances, but in the remainder no reducing substances were detected.

The effect of allowing a sugar-containing stool to soak into a napkin was observed (Table II). A stool that contained $1 \%$ reducing substances when freshly and completely collected on plastic, was
TABLE I

Effect of Hydrolysis of Faeces on Reducing Substances

\begin{tabular}{|c|c|c|c|}
\hline \multirow{2}{*}{ Case No. } & \multicolumn{2}{|c|}{ Reducing Substances } & \multirow{2}{*}{$\begin{array}{c}\text { Sucrose } \\
\text { Shown on } \\
\text { Chromatogram }\end{array}$} \\
\hline & $\begin{array}{c}\text { Before } \\
\text { Hydrolysis }\end{array}$ & $\begin{array}{c}\text { After } \\
\text { Hydrolysis }\end{array}$ & \\
\hline $\begin{array}{r}1 \\
1 \\
2 \\
3 \\
4 \\
4 \\
5 \\
6 \\
6 \\
7 \\
8 \\
8 \\
9 \\
10 \\
10 \\
11 \\
12 \\
13 \\
13 \\
14 \\
15 \\
16 \\
16 \\
17 \\
18 \\
19 \\
19 \\
20\end{array}$ & $\begin{array}{c}0 \cdot 25-0 \cdot 5 \% \\
0 \cdot 25-0 \cdot 5 \% \\
0 \cdot 25 \% \\
0 \cdot 25 \% \\
\text { Nil } \\
\text { Nil } \\
0 \cdot 25 \% \\
0 \cdot 25-0 \cdot 5 \% \\
0 \cdot 75 \% \\
1 \% \\
0 \cdot 25 \% \\
0 \cdot 5 \% \\
0 \cdot 25 \% \\
1 \% \\
0 \cdot 5-0 \cdot 75 \% \\
0-0 \cdot 25 \% \\
\mathrm{Nil} \\
\mathrm{Nil} \\
0 \cdot 25 \% \\
\mathrm{Nil} \\
0 \cdot 75 \% \\
0 \cdot 25 \% \\
0 \cdot 75 \% \\
0 \cdot 25 \% \\
0 \cdot 75 \% \\
0 \cdot 25 \% \\
0 \cdot 25-0 \cdot 5 \% \\
1 \%\end{array}$ & $\begin{array}{c}0 \cdot 5 \% \\
0 \cdot 5 \% \\
1 \% \\
0 \cdot 75 \% \\
0 \cdot 75 \% \\
0 \cdot 5 \% \\
0 \cdot 25-0 \cdot 5 \% \\
0 \cdot 75 \% \\
1 \% \\
1-2 \% \\
0 \cdot 5 \% \\
0 \cdot 75 \% \\
0 \cdot 75 \% \\
1-2 \% \\
1-2 \% \\
0 \cdot 5 \% \\
0 \cdot 25-0 \cdot 5 \% \\
0 \cdot 5 \% \\
0 \cdot 5 \% \\
0 \cdot 25-0 \cdot 5 \% \\
1 \% \\
0 \cdot 75 \% \\
2 \% \\
0 \cdot 25-0 \cdot 5 \% \\
1-2 \% \\
0 \cdot 75 \% \\
0.5-0 \cdot 75 \% \\
1-2 \% \\
\end{array}$ & $\begin{array}{l}- \\
- \\
- \\
- \\
- \\
+ \\
+ \\
+ \\
- \\
- \\
- \\
- \\
- \\
- \\
+ \\
- \\
- \\
+\end{array}$ \\
\hline
\end{tabular}

placed on an ordinary napkin; part was immediately removed for examination and portions were removed at 15-minute intervals for 1 hour, diluted immediately with water, homogenized, and tested for reducing substances. In 15 minutes only the solid portion of the stool was left, which contained $\frac{1}{4}-\frac{1}{2} \%$ reducing substances, and this continued for the 60 minutes of the study. This is a nonsignificant level.

In all, 37 stools were formed. As expected, none of these stools contained a significant amount

TABLE II

Effect of Allowing Stool to Soak into Napkin

\begin{tabular}{c|c|c|c}
\hline Time & Nature of Stool & $\begin{array}{c}\text { Reducing } \\
\text { Substances }\end{array}$ & $p H$ \\
\cline { 1 - 2 } $\begin{array}{c}\text { Before Soaking } \\
0 \text { min }\end{array}$ & $\begin{array}{c}\text { Yellow, green, } \\
\text { watery and curds }\end{array}$ & $1 \%$ & $>5$ \\
After Soaking & Yellow, green curds & $0.5-0.75 \%$ & $>5$ \\
0 min & and little fluid & $0.25-0.5 \%$ & $5-6$ \\
15 min & Yellow, green curds & $0.25-0.5 \%$ & $5-6$ \\
$30 \mathrm{~min}$ & Yellow, green curds \\
$60 \mathrm{~min}$ & Yellow, green curds & $0.25-0.5 \%$ & $5-6$ \\
\hline
\end{tabular}




\section{Role of Chemical Examination of the Stool in Diagnosis of Sugar Malabsorption in Children 59}

of reducing substances. One contained $\frac{1}{4} \%$ and 8 contained between 0 and $1 \%$; the remaining ones contained no sugar at all.

Chromatography for sugar. 5 principal patterns were observed chromatographically in those cases in which sugar was present in the stools, though there was considerable variation in the density of the sugar spot in individual chromatograms. These are illustrated in Fig. 3.

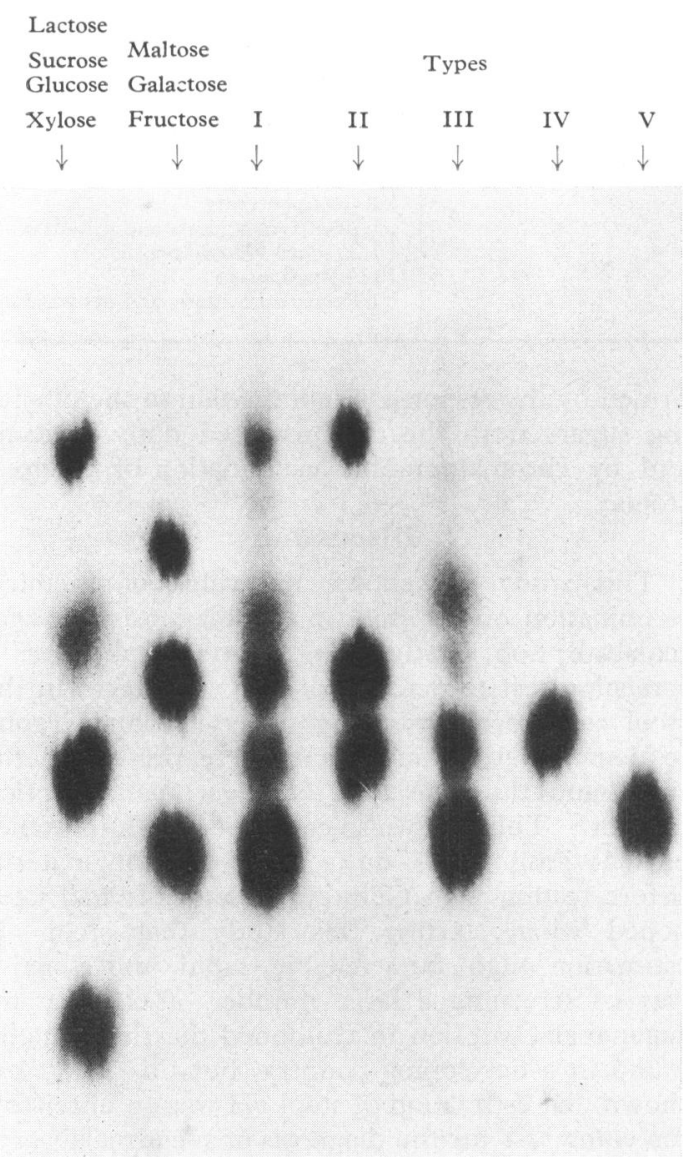

FIG. 3.-Stool chromatogram patterns I-V. Markers for 7 sugars are shown on the two left-hand columns.

Pattern I was characterized by the presence of lactose, sucrose, galactose, glucose, and fructose in the stools of children having sweetened condensed milk diluted 1 in 8 as their feed. This feed contains lactose $1.4 \mathrm{~g} / 100 \mathrm{ml}$ and sucrose 5.3 $\mathrm{g} / 100 \mathrm{ml}$. This pattern was interpreted as evidence of lactose and sucrose malabsorption.
Pattern II was characterized by the presence of lactose, galactose, and glucose in the stool and when found in children having feeds based on cow's milk was interpreted as evidence of lactose malabsorption.

Pattern III was infrequently seen and in this pattern the principal sugars in the stool were fructose and glucose, some sucrose, and sometimes traces only of lactose and galactose. This pattern was found in infants having a sucrose-containing feed such as sweetened condensed milk 1 in 8 , and indicated that these children had evidence of sucrose malabsorption.

Pattern IV was found in infants having a glucosecontaining feed such as Glucose Nutramigen (Mead Johnson) or D.S.I. (Nestlé-an experimental feed not yet marketed) and indicated glucose malabsorption.

Pattern V was found in infants who had sugar in their stools while having the fructose based formula Galactomin 19 (Trufood) and thus indicated the presence of fructose malabsorption.

The chromatograms of all patients could be placed in one of these 5 categories, but the relative density of the sugar spots varied from stool to stool. In some stools there was also a trace of maltose and in others spots of varying intensity were observed that had a shorter run than lactose. These spots were interpreted as having the characteristics of oligosaccharides. In the control children who had $1 \%$ reducing substances in their stools, traces of these short run substances were seen together with traces of galactose and glucose.

In 4 children, more than one type of chromatogram was found, i.e. different patterns were seen when the feeds were changed. In 1 child a chromatogram consistent with lactose and sucrose malabsorption was seen (Fig. 4), but on a glucose-containing feed the chromatogram of glucose malabsorption was found. This child still had fructose in her stools while having a fructosecontaining formula (Galactomin 19), i.e. she had total monosaccharide malabsorption. Introduction of a carbohydrate-free formula to the diet led to cessation of diarrhoea and disappearance of sugar from the chromatogram.

Two of the remaining children had pattern I or II on their first chromatogram and pattern IV while on Nutramigen, i.e. they had glucose malabsorption. The fourth child when first seen was having Nutramigen and the stool chromatogram revealed pattern IV. Starting her on Galactomin 19 produced stools which chromatographically had pattern V, i.e. she too had total monosaccharide malabsorption. 


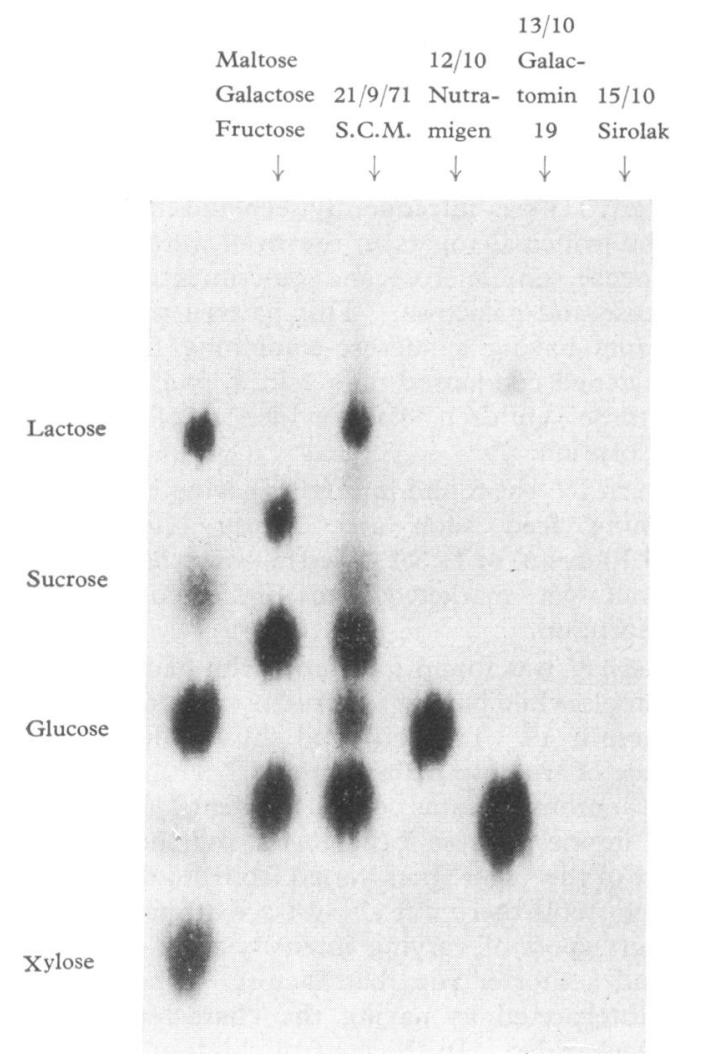

FIG. 4.-Stool chromatogram from child with malabsorption of lactose, sucrose, glucose, and fructose; marker sugars on left.

The distribution of these patterns is listed in Table III, together with the clinical diagnosis. In all cases sugar malabsorption was secondary to some other primary disease process, and in all, except 2 children who died from intercurrent infection, it was observed to be a transient phenomenon.

Clinical diagnosis of sugar malabsorption. A diagnosis of sugar malabsorption was made in 33 children, all of whom were treated by dietary manipulation. This diagnosis was based on the consistent finding of $\frac{1}{2} \%$ or more of reducing substances in a loose stool. All such children when placed on the appropriate elimination diet had relief from diarrhoea. A diagnosis of the type of sugar malabsorption present was made, firstly on the basis of the sugars noted to be present in the stool chromatogram, combined with knowledge of the sugar content of the infant's feed, and con-
TABLE III

Relation of Sugar Chromatogram Pattern to Clinical Condition

\begin{tabular}{|c|c|c|}
\hline $\begin{array}{l}\text { Chromatogram } \\
\text { Pattern }\end{array}$ & $\begin{array}{l}\text { No. } \\
\text { of } \\
\text { Cases }\end{array}$ & Diagnosis \\
\hline I & 11 & $\begin{cases}1 & \text { Gastroenteritis } \\
1 & \text { Neonatal surgery } \\
1 & \text { Recurrent acidosis and dehydration } \\
9 & \text { Gastroenteritis } \\
4 & \text { Neonatal surgery } \\
2 & \text { Giardiasis }\end{cases}$ \\
\hline II & 19 & $\begin{cases}1 & \text { Meningocele } \\
1 & \text { Colitis } \\
1 & \text { Meningitis } \\
1 & \text { Turner's syndrome }\end{cases}$ \\
\hline III & 2 & 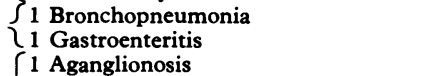 \\
\hline IV & 4 & $\begin{cases}1 & \text { Gastroenteritis } \\
1 & \text { Recurrent acidosis and dehydration } \\
1 & \text { Tracheo-oesophageal fistula }\end{cases}$ \\
\hline V & 2 & $\begin{cases}1 & \text { Aganglionosis } \\
1 & \text { Recurrent acidosis and dehydration }\end{cases}$ \\
\hline
\end{tabular}

firmed by the response to elimination of the offending sugars from the diet, assessed both clinically and by chromatographic examination of progress stools.

\section{Discussion}

This study has shown the value of chemical examination of the stool in the diagnosis of sugar malabsorption, firstly using Clinitest tablets as a screening test to detect reducing substances in the stool and, secondly, using paper chromatography to demonstrate which sugars were present in the stool, and thus the type of sugar malabsorption present. This study also confirmed the importance of collecting stools on a nonabsorbent material before testing with Clinitest tablets. It had been hoped when starting this study that stool $p \mathrm{H}$ estimation might be a reliable, rapid, and effective way of screening a large number of children for sugar malabsorption in childhood diarrhoeal states found in a developing country, but this study has shown that estimation of stool $p \mathrm{H}$ was an unreliable screening test for the diagnosis of sugar malabsorption in a large group of children, though perhaps a useful observation to be made in an individual patient.

Davidson and Mullinger (1970) have thrown some doubt on the reliability of finding excess reducing substances in the stools as a screening test for sugar malabsorption in neonates, as they found abnormal amounts of reducing substances in the stools of normal neonates. They stated, however, that these infants passed pasty or curdy liquid stools, and not the typical watery stools of classical 


\section{Role of Chemical Examination of the Stool in Diagnosis of Sugar Malabsorption in Children 61}

sugar malabsorption. None of our controls, which included 9 neonates, had more than $\frac{1}{4} \%$ reducing substances in their stools, but not all our infants with clinical sugar malabsorption had the classical watery stools referred to above. Nonetheless, all children with more than $\frac{1}{2} \%$ reducing substances had loose stools and responded to dietary elimination of the offending sugar. The consistent finding of more than $\frac{1}{2} \%$ reducing substances in loose stools is an indication for dietary management in any infant or child with diarrhoea.

This study demonstrates that an increase in the amount of reducing substances after acid hydrolysis of stools may be an unreliable guide to the diagnosis of sucrose malabsorption. An apparent increase in the level of stool reducing substances or even the appearance of a significant level in a stool previously free of sugar may not be accompanied by the finding of sucrose in the stool chromatographically. This apparent increase in reducing substances after acid hydrolysis of the stool in the absence of sucrose may be due to a colour change which may reflect an alteration in the state of oxidation of the bile pigment content of the stool, after treatment with hydrochloric acid and boiling of the mixture.

Chromatographic examination of the stools is a useful aid in the diagnosis of sugar malabsorption, particularly as a guide to the type of sugar malabsorption present. It is of special value in infants with monosaccharide malabsorption where there have been rapid changes in the type of feeds given to the infant. It may also be of value in demonstrating dietary error by revealing an unexpected sugar in the stool. Finally, this method of examination is necessary if the diagnosis of sucrose malabsorption is to be made from investigation of the child's stools.

All children in this study had secondary sugar malabsorption and this was a transient phenomenon. If a primary sugar malabsorption is suspected, e.g. congenital alactasia or congenital sucrase-isomaltase deficiency, small intestinal enzyme assay for disaccharidases is indicated to make a definitive diagnosis, but in children with secondary sugar malabsorption, chemical examination of properly collected stools enables a clinical diagnosis of sugar malabsorption and its type to be made.

\section{REFERENCES}

Davidson, A. G. F., and Mullinger, M. (1970). Reducing substances in neonatal stools detected by Clinitest. Pediatrics, 46, 632.

Davidson, M. (1967). Disaccharide intolerance. Pediatric Clinics of North America, 14, 93.

Durand, P., Martino, A. M., and Lamedica, G. M. (1961). Diagnosis of carbohydrate-intolerance diarrhoeas by stool chromatography. Lancet, 2, 374.

Holzel, A. (1967). Sugar malabsorption due to deficiencies of disaccharidase activities and monosaccharide transport. Archives of Disease in Childhood, 42, 341.

Kerry, K. R., and Anderson, C. M. (1964). A ward test for sugar in faeces. Lancet, $1,981$.

Kerry, K. R., and Townley, R. R. W. (1965). Genetic aspects of intestinal sucrase-isomaltase deficiency. Australian Paediatric fournal, 1, 223.

Smith, I. (1958). Chromatographic Techniques: Clinical andBiochemical Applications, p. 164. Heinemann, London.

Correspondence to Dr. J. A. Walker-Smith, Institute of Child Health, Royal Alexandra Hospital for Children, Camperdown, N.S.W. 2050, Australia. 